\title{
O PROFESSOR QUE ENSINA MATEMÁTICA NOS ANOS INICIAIS: UMA ABERTURA AO CONTÍNUO ACONTECER HISTÓRICO
}

\author{
EL PROFESOR QUE ENSEÑA MATEMÁTICAS EN LOS AÑOS INICIALES: UNA \\ APERTURA AL CONTINUO OCORRE HISTÓRICO
}
THE TEACHER WHO TEACHES MATHEMATICS IN THE EARLY YEARS: AN OPENING TO CONTINUOUS HISTORICAL EVENTS

\author{
Luciane Ferreira MOCROSKY ${ }^{1}$ \\ Nelem ORLOVSKI ${ }^{2}$ \\ Henrique $\mathrm{LIDIO}^{3}$
}

RESUMO: Este artigo apresenta aspectos históricos da formação do professor dos Anos Iniciais do Ensino Fundamental. Numa perspectiva filosófica-hermenêutica, lança luz sobre significados atribuídos ao termo formação e, com as compreensões possibilitadas pelo estudo interpretativo-reflexivo, evidencia registros históricos à Pedagogia como lócus de formação acadêmica do professor dos Anos Iniciais. Pela descrição do que veio como herança da historicidade do curso de Pedagogia, o texto explicita entendimentos acerca do modo como a matemática se presentifica em tal graduação. Como síntese compreensiva, destaca que a Pedagogia permanecerá sempre em constituição, haja vista que a identidade do curso como formador do professor dos Anos Iniciais e, mais ainda, do professor de matemática, está a caminho, construindo-se, deixando em aberto possibilidades de a formação do professor se dar.

PALAVRAS-CHAVE: Educação matemática. Formação inicial. Pedagogia. Anos iniciais.

RESUMEN: El objetivo de este texto analítico-reflexivo es exponer aspectos históricos de la formación inicial del profesor polivalente, pedagogo, que ha actuado, entre otras áreas, en los años iniciales de la Enseñanza Fundamental. El texto comienza lanzando luz sobre significados atribuidos al término formación, por los sentidos provenientes de los estudios de textos sobre la temática de formación en una perspectiva filosófica- hermenéutica. Con las comprensiones posibilitadas, sigue en busca de registros históricos a la Pedagogía como locus de formación académica del profesional que actuará como docente en los años iniciales de la Educación Básica. Por ese camino, presenta una descripción de lo que vino como herencia de la historicidad de estos cursos, explicitando entendimientos acerca del modo en que las matemáticas se presentifica en tal grado. Como síntesis comprensiva el estudio destaca que la Pedagogía permanecerá siempre en constitución, habida cuenta de que la

${ }^{1}$ Universidade Tecnológica Federal do Paraná (UTFPR), Curitiba - PR - Brasil. Professora do DAMAT, do PPGFCET e do PPGECM (UFPR). Integrante dos grupos de pesquisa FEM e GEForProf. ORCID <http://orcid.org/0000-0002-8578-1496>. E-mail: mocrosky@ gmail.com

${ }^{2}$ Universidade Estadual Paulista Júlio de Mesquita Filho (UNESP), Rio Claro - SP - Brasil. Doutoranda do Programa de Pós-Graduação em Educação Matemática. Integrante dos grupos de pesquisa FEM e GEForProf. Professora da Rede Municipal de Ensino de Curitiba (RME). E-mail: orlovskice@ yahoo.com.br

${ }^{3}$ Secretaria de Estado da Educação do Paraná - (SEED-PR), Piraquara - PR - Brasil. Professor da Educação Básica. E-mail: henriquelidio@bol.com.br 
identidad del curso como formador del profesor de los años iniciales, y más aún, del profesor de matemáticas, está en camino, haciéndose, dejando en abierto posibilidades para la formación del professor.

PALABRAS-CLAVE: Educación matemática. Formación inicial. Pedagogía. Años iniciales.

ABSTRACT: In this text are exposed historical aspects of the teacher training of the initial years of elementary school. From a philosophical-hermeneutical perspective, light is shed on meanings attributed to the term formation. With the understandings made possible by the interpretative-reflective study, it is evident historical records to Pedagogy as a locus of academic formation of this professional. It presents a description of what came as an inheritance of the historicity of these courses, explaining understandings about how mathematics presents itself in such graduation. As a comprehensive synthesis, it should be emphasized that Pedagogy will always remain in its constitution, given that the identity of the course as teacher's trainer in the early years, and even more so, the mathematics teacher, is on the way, leaving open possibilities for teacher training to take place.

KEYWORDS: Mathematical education. Initial formation. Pedagogy. Early years.

\section{Introdução}

O desafio de formar professores para ensinar matemática na Educação Básica tem sido o solo de nossas reflexões e atividades profissionais. Pesquisas realizadas sobre formação no campo da Educação Matemática têm revelado que esta continua a ser "um conhecimento parcelado, incompleto", mesmo após o crescimento das pesquisas nas últimas décadas (ANDRÉ, 2011; FIORENTINI et al., 2016). Entender quais sentidos são atribuídos à formação do professor dos Anos Iniciais, no percurso educacional histórico, é importante para que seja possível nos compreendermos em nosso próprio desenvolvimento profissional, enquanto formadores de docentes para Educação Básica, bem como para sustentar outras caminhadas em torno do tema.

Nesse texto, expomos aspectos de investigações maiores (LIDIO, 2015; ORLOVSKI, $2014)^{4}$, que tiveram por tema os entendimentos de formação do professor que ensina Matemática nos Anos Iniciais, na perspectiva do que é enviado pela história dos cursos de Pedagogia. Trazemos, assim, compreensões-interpretações sobre a temática, na região de inquérito da Educação Matemática, possibilitadas pelo estudo analítico-reflexivo da literatura, incluindo a legislação. Buscamos, ainda, compreender a Pedagogia como lócus de formação

\footnotetext{
4 Trata-se de duas pesquisas qualitativo-fenomenológicas que interrogaram o fenômeno 'formação do professor que ensina Matemática nos Anos Iniciais', orientadas pela primeira autora.
} 
inicial/acadêmica do profissional que atuará como docente nos Anos Iniciais da Educação Básica, questionando os modos pelos quais a matemática se presentifica nessa trajetória.

$\mathrm{Na}$ primeira seção explicitamos compreensões de formação, lançando luz aos significados atribuídos a esse termo, pautando-nos em sua historicidade e no estudo hermenêutico de textos que tratam da formação numa perspectiva filosófica.

$\mathrm{Na}$ sequência, apresentamos uma breve descrição ao visar intencionalmente o acontecer histórico dos cursos de Pedagogia, observando o momento em que estes passam a se responsabilizar por formar professores dos Anos Iniciais.

$\mathrm{Na}$ terceira seção damos atenção aos modos como a matemática veio se presentificando nos cursos de Pedagogia.

Finalmente, expomos uma síntese compreensiva do que entendemos nesse trajeto de estudo - que nos foi também formativo - e que mostrou-se aberto, solicitando novos questionamentos, tal como uma das características básicas da formação: o movimento de devir, de enlace contínuo entre formas e ações, ações e formas.

\section{Formação: o entrecruzamento de formas e ações, de ações e formas}

Desde meados do século XIX vem crescendo a preocupação com a questão da formação. À época, as universidades já eram contestadas por não conseguirem formar um estudante capaz de elaborar uma imagem própria do mundo, dadas as influências externas, como os interesses de classe sociais em perseguir metas utilitárias.

No século XX, reforça-se uma ideia que já permeava o vocabulário alemão desde fins do século XVIII - a Bildung, que é um termo de alta complexidade e com extensa aplicação nos campos da pedagogia, da educação e da cultura, sendo até hoje usado amplamente na língua alemã, com significação filosófica, estética, pedagógica e ideológica sem igual. Gadamer (1997), em sua obra Verdade e Método, fala da importância do termo Bildung, traduzido como formação cultural:

O conceito de formação [...] foi, sem dúvida alguma, o mais alto pensamento do século XVIII e justamente esse conceito caracteriza o elemento em que vivem as ciências do espírito do século XIX. [...]. Com o conceito de formação torna-se nitidamente perceptível quão profunda é a mudança espiritual que continua nos fazendo parecer contemporâneos do século de Goethe, enquanto que, em contrapartida até mesmo a época do Barroco já parece se situar num passado pré-histórico (GADAMER, 1997, p. 47). 
Cultura aqui entendida como o que se cultiva. E o que vem sendo cultivado? Para Gadamer cultiva-se o que existe, o que se produz pelo produto, ou seja, o termo vem envolto em ideias que mistificam a forma como a expressão maior da formação. Por aí, este autor nos expõe uma compreensão de formação como um conceito genuinamente histórico, que desde a Idade Média vem se transformando, mas sempre à sombra do que a forma ideal, perseguida, revela.

Gadamer (1997) chama atenção para o fato de que a palavra forma tem sido separada de seu significado, cuja interpretação tem sido "puramente dinâmica e natural". O autor explica que isto não é por acaso, pois formação (Bildung) encontra-se na palavra Bild (imagem), abrangendo 'cópia' (Nachbild) e 'modelo' (vorbild), correspondendo "a uma frequente transferência do devir para o ser”. Com este filósofo, entendemos que o solo cultural que tem possibilitado compreender a formação tem lançado luz ao produzido, pela possibilidade de exposição de um modelo ideal, em que o produzir uma forma já aponta para o resultado. $\mathrm{O}$ foco incide mais sobre o produto vislumbrado. Há a necessidade cultural de se ter um modelo a ser copiado e este se estabelece como a expressão maior da formação.

Gadamer (1997) continua e expõe que esse entendimento solicita ser superado “[...] porque o resultado da formação não se produz na forma de uma finalidade técnica, mas nasce do processo interno de constituição e deformação e, por isso, permanece em constante evolução e aperfeiçoamento" (GADAMER, 1997, p. 50). Para este filósofo, a formação não se traduz num resultado a ser alcançado, pois se assim fosse, a ação que permite moldar formas seria compreendida como um meio para um fim, distante da contínua constituição de modos de ser do ser humano.

Compreendemos, com Gadamer (1997), que há uma preocupação com o que a linguagem pode expressar e com os significados manifestados, mudando-se o modo de pensar para uma perspectiva que articula a preocupação com o sentido que isso faz para quem está atentamente questionando a formação.

O que este estudo nos diz? Pensamos que formação pode ser compreendida como um processo contínuo de devir; como movimento ininterrupto em que ação e forma estão sempre em marcha, dando-se mutuamente, ou seja, a formação de professores passa pelo desenvolvimento de experiências de produção do ser. É muito importante considerar e entender trajetórias, processos e percursos, ou seja, pensar a formação do sujeito-professor é pensar a produção de si mesmo.

Com isso, entendemos que o caminho hermenêutico viabiliza possibilidades para compreensão, pois trata de um processo de interpretação da própria experiência como um ato 
de construção de sentidos de si. Gadamer (1997) acreditava na hermenêutica como uma reflexão permanente sobre aquilo que deve ser a configuração da vida humana, e:

[...] não é uma metodologia das ciências humanas, mas uma tentativa de compreender o que são verdadeiramente as ciências humanas para além de sua autoconsciência metodológica, e que as liga à totalidade de nossa experiência do mundo (GADAMER, 1997, p. 31).

A hermenêutica preocupa-se com a formação ética da existência, reconhecendo que o ser humano é um ser em formação, com o sentido e o modo de se constituir sempre inacabados. Nesse modo de se lançar às compreensões, a formação não se resume à aplicação mecânica da técnica. Vai além, ao buscar outras formas de conhecer a realidade e não se prender a um procedimento mecânico, razão pela qual é chamada de hermenêutica filosófica, compreendida como uma arte.

Formo-me vivendo e vivo me formando e, nessa perspectiva, viver em formação e falar sobre formação faz parte da nossa história de vida, desfazendo a imagem das amarras de compreendê-la como um "objeto histórico" a ser conhecido, "para aprender a reconhecer no objeto o outro de si próprio e com isso tanto quanto um pouco o outro" (GADAMER, 1997, p. 81), ou seja, para compreendermo-nos seres em formação, sendo, acontecendo, formando-nos e formando os outros.

Nesse sentido, a ideia não é compreender o 'ser' e sim de que maneira a compreensão é ' $\operatorname{ser}^{5}$ ', portanto um processo infindável. Isso quer dizer que nunca se conclui, que sempre está em movimento de acontecer, compreender e compreender-se como seres que se formam e formam os outros.

Ao buscarmos entendimentos de formação, o que se mostrou a nós foi o contínuo constitutivo humano em seu modo de ser. Assim, ao perguntarmos sobre a formação do professor, questionamos o processo histórico institucionalizado para 'formar' professores nos cursos de Pedagogia. O que se abre à compreensão do curso de Pedagogia em seu modo de 'ser', no solo legal da educação brasileira?

\section{O curso de Pedagogia... traços de uma historicidade vigente}

Como vimos entendendo, os cursos de Pedagogia vêm se constituindo historicamente desde o começo do século XIX. O preparo para ensinar as primeiras letras, bem como o domínio do método, no Brasil, surgiu em 1820, na Província do Rio de Janeiro, com uma

\footnotetext{
5 Gadamer (1997) se refere ao entendimento de "ser" fundamentado em Martin Heidegger.
} 
escola para pessoas que se lançassem ao desafio de se tornar docentes. Porém essa preparação não tinha embasamento teórico, era realizada apenas na prática. Compreensões mais pontuais dar-se-iam no estabelecimento em que o docente fosse trabalhar e seriam de responsabilidades dos professores adjuntos (TANURI, 2000).

Procurou-se uma nova forma de educação, as chamadas escolas de primeiras letras de ensino mútuo, criadas em 1823. Segundo Tanuri (2000), não foram obtidos bons resultados, possivelmente pela característica do ensino mútuo - também conhecido por Método Lancaster - se constituir por classes heterogêneas e numerosas, metodicamente organizadas para imprimir um ritmo que garantisse disciplina e possibilitasse o ensino, sendo este marcado pela repetição e memorização (ORLOVSKI; MOCROSKY, 2016).

Na década seguinte surgiram as primeiras Escolas Normais, criadas pela Lei $\mathrm{n}^{\circ}$. 10, de 1835, na província do Rio de Janeiro. Entretanto, somente partir do ano de 1840 que ressurgiu a Escola Normal com um programa (ou ementa) de conteúdo renovado, segundo a qual:

[...] o curso teria duração de três anos, compreendendo o seguinte programa: língua nacional, caligrafia, doutrina cristã e pedagogia (primeira cadeira); aritmética, inclusive metrologia, álgebra até equações do segundo grau, noções de geometria (teoria e prática), na segunda cadeira; elementos de cosmografia e noções de geografia e história principalmente do Brasil, o que seria a terceira cadeira. (TANURI, 2000, p. 64).

A primeira escola normal brasileira foi criada na Província do Rio de Janeiro, contemplando o seguinte currículo: "ler e escrever pelo método lancasteriano; as quatro operações e proporções; a língua nacional; elementos de geografia; princípios de moral cristã" (TANURI, 2000, p. 64). A mesma autora explicita que ao final dos anos de 1870 essas escolas também fecharam devido à falta de alunos, problemas administrativos e falta de interesse da população pela profissão docente. Tanuri (2000) esclarece que a partir do decreto de Leôncio de Carvalho (1879), o currículo das escolas de formação de professores foi se modificando e, no período da República, caberia apenas continuar a desenvolver essa tarefa e a qualificar cada vez mais os cursos (ou escolas) de formação docente. Sobre estes aspectos históricos do curso de Pedagogia no Brasil, Brito (2006) afirma que seu início se deu a partir do DecretoLei $\mathrm{n}^{\circ} 1.190 / 1939$, no qual as primeiras propostas incluíam o estudo das formas de ensinar, definido como o lugar de formar "técnicos em educação". Nesse período, os professores que buscavam por essa graduação eram, quase que exclusivamente, profissionais que já estavam no mercado de trabalho, e que levavam para dentro das faculdades a experiência que possuíam, buscando apenas o cunho científico/acadêmico para fundamentar suas práticas em sala de aula. 
Nesse olhar para, vemos indícios do surgimento legal da Pedagogia e percebemos que ela nasce no solo do processo educacional institucionalizado, orientado pela necessidade da cientificidade, constituindo-se uma necessidade social de buscar meios legais para validar cientificamente a educação que acontecia nas escolas. No entanto, atentemos para o fato de que a educação, a formação de professores e alunos, já acontecia há muitos anos, e a questão era a formação em nível superior. A pedagogia como um curso de graduação surge nesse cenário legal, na esteira da necessidade formativa em nível superior para docentes, onde compreendemos estar a Pedagogia para validar, de algum modo, o que posteriormente veio caracterizar sua função primordial: formar professores para os Anos Iniciais.

No entanto, o curso de Pedagogia implementado pelo Decreto-Lei $n^{\circ}$ 1.190/1939 inicialmente funcionava no chamado 'padrão federal', conhecido como modelo ' $3+1$ ', em que o aluno fazia três anos de curso e recebia o título de Bacharel em Pedagogia e, caso desejasse, poderia cursar um ano a mais para obter o grau de Licenciado em Pedagogia. Neste momento o aluno estudaria Didática, o que nos mostra que um dos aspectos que orientou seu surgimento, de formar para a escola primária, foi deslocado a segundo plano, pois a validação legal para atuar nos Anos Iniciais era 'complementar', ou seja, em um ano 'a mais', se assim o egresso desejasse. Com isso, vemos que desde a sua origem legal, o curso de Pedagogia já nasce com uma 'função dupla': tratar da formação de pessoas para a ciência da Educação e, complementarmente, para a prática da Educação (professores dos Anos Iniciais) com perspectivas diferenciadas.

Há, visivelmente, uma separação que só foi aumentando. A partir de 1943, os bacharéis em Pedagogia poderiam preencher os cargos de técnicos em Educação no então Ministério da Educação e Saúde enquanto os licenciados tinham um campo mais definido - o Curso Normal, cujas disciplinas do currículo eram, em sua maioria, abordadas no curso de Pedagogia, podendo também lecionar Filosofia, História Geral e do Brasil, no $1^{\circ}$ e $2^{\circ}$ ciclos do Ensino Secundário ${ }^{6}$ e, também, Matemática no $1^{\circ}$ ciclo. $\mathrm{O}$ campo de atuação do pedagogo, nesse período, era pulverizado e não apresentava normativas formais que subsidiassem sua 'personalidade' no cenário da educação institucionalizada, do que arriscamos dizer que ele já nasce com uma 'dupla personalidade' que vai se constituindo por oposições, quando seria de se esperar por articulações.

Pela via percorrida, constatamos que o curso de Pedagogia, no período de 1939 a 1970, não parecia ter como um de seus objetivos fundamentais a preocupação com a formação

${ }^{6} \mathrm{O}$ ensino secundário era dividido em duas etapas: o ginásio, no $1^{\text {o }}$ ciclo, e o clássico e o científico, no $2^{\circ}$ ciclo. 
disciplinar do aluno egresso, mesmo considerando as necessidades explicitadas anteriormente, como a de formar o profissional atuante em sala de aula. Utilizamos o termo disciplinar no sentido das disciplinas escolares que esse aluno precisaria dominar, uma vez que as lecionaria às crianças. Observação essa que pode subsidiada pela grade curricular do citado curso na época, tal como explicita Curi (2004). No campo da Matemática, apenas duas disciplinas eram abordadas: Complementos de Matemática e Estatística Educacional, mas sem o enfoque para atuar com alunos dessa etapa da Educação Básica, já que seu objetivo era formar o professor das disciplinas pedagógicas do Curso Normal.

A partir do Decreto do Conselho Federal de Educação no ${ }^{\circ}$ 252/1969, o curso de Pedagogia foi organizado em duas partes: uma comum e outra diversificada. Esse núcleo comum compreenderia disciplinas voltadas à Educação, já a parte diversificada incluía magistério dos cursos normais, atividades de orientação, inspeção, administração e supervisão. Desde a sua criação, muitas leis e pareceres procuraram modelar, dar uma forma ideal a este curso. Atualmente, com a possibilidade de trabalhar com a formação desde a Educação Infantil, Anos Iniciais do Ensino Fundamental e como técnico pedagógico (antigamente denominado supervisor ou orientador), o campo de atuação desse profissional em nível superior parece começar a mostrar uma identidade, mas nos questionamos: não se trataria antes de uma 'múltipla identidade'?

Pelas leituras efetuadas, o curso de Pedagogia nem sempre teve seus objetivos estabelecidos como na atualidade. Trabalhar numa área tão abrangente, podendo executar funções variadas, foi algo conquistado ao longo de muitos anos, dada a busca de uma identidade para o curso.

Segundo Curi (2005), a partir da Lei 5.692/71, o professor dos Anos Iniciais do Ensino Fundamental poderia ser habilitado nos cursos de Pedagogia. Esses cursos tinham duração mínima de 2.200 horas distribuídas em no mínimo três e no máximo sete anos letivos, sendo que o currículo mínimo do curso compreendia uma parte comum a todas as habilitações e outra diversificada, em função das habilitações específicas oferecidas pela instituição e escolhidas pelo aluno, que poderia optar por, no máximo, duas delas. Mas, o que é a Pedagogia e quem é o pedagogo?

Libâneo (2006) mostra um emaranhado de possibilidades e define a pedagogia como ciência e o pedagogo como um profissional com funções múltiplas, e não tece um terreno de atuação claro para os discentes desse curso, embora a docência seja a mais evidente. No entanto, afirma de modo enfático: a base de um curso de pedagogia não pode ser a docência. 
Todo trabalho docente é trabalho pedagógico, mas nem todo trabalho pedagógico é trabalho docente.

Compreendemos que a questão da múltipla identidade, pela via legal, não estaria centrada nas atribuições formativas no curso de Pedagogia, e pudemos ver isso pela própria trajetória histórica desse curso. Assim, a questão que nos causa perplexidade, ainda ocultada, muda de forma: a formação de professores atuantes nos Anos Iniciais em nível superior seria complementar, coadjuvante nos cursos de pedagogia? Ou ainda, a pedagogia, com sua 'múltipla identidade' de nascença, tem como sustentar a formação de um profissional múltiplo? Seria o professor dos Anos Iniciais um profissional de múltiplas identidades, ou seria essa multiplicidade um modo de defini-lo como profissional, portanto a sua identidade?

O curso de Pedagogia, na atualidade, se destina a formar o pedagogo especialista, isto é, um profissional qualificado para atuar em vários campos educativos, para atender demandas socioeducativas (de tipo formal, não-formal e informal) decorrentes de novas realidades, diferentes tecnologias, atores sociais diversos, ampliação do lazer, mudanças nos ritmos de vida e sofisticação dos meios de comunicação. Segundo o Parecer n ${ }^{\circ}$, de 13 de dezembro de 2005, o pedagogo deve "aplicar modos de ensinar diferentes linguagens: Língua Portuguesa, Matemática, Ciências, História, Geografia, Artes, Educação Física, de forma interdisciplinar e adequada às fases do desenvolvimento humano, particularmente de crianças" (BRASIL, 2005).

$\mathrm{Na}$ perspectiva sociocultural vivida na atualidade, o que vemos é que a face que mais se evidencia na profissão do pedagogo, o ensino das noções básicas das diferentes áreas do conhecimento, ainda permanece obscurecida na própria legislação, e ao mesmo tempo reivindica que este futuro professor tenha modos de ensinar diferentes, conforme a faixa etária em que for atuar. Como analisar um curso que tem várias possibilidades e focar essa formação sólida para a docência, já que a Pedagogia está em busca de sua identidade? Como resguardar a formação sólida para a docência em um curso de identidade múltipla?

Aliás, por onde se orienta essa multiplicidade de identidades que se tem construído, senão pela docência? Por mais que o curso forme esse profissional para atuar em várias direções, o que a própria Educação Básica anseia neste profissional?

Entendemos, então, que a própria multiplicidade de identidades do curso de Pedagogia se mantém em formação, em movimento contínuo de devir. Entretanto, por esse caminho, se evidencia uma formação carente de sentido orientador à docência, ou seja, de suas várias faces talvez a que menos tenha espaço no lócus de sua constituição seja a docência nos Anos Iniciais. 
Se o curso de Pedagogia permanece se constituindo em relação às suas funções, suas características e à sua própria múltipla identidade, perguntamos: como a matemática vem se presentificando nessa dinâmica 'viva' de ser da Pedagogia? Que forma a matemática vai "ganhando" nessa dinâmica do acontecer histórico do curso de Pedagogia?

\section{Na Pedagogia, entre Educação e formação, como se presentifica a matemática?}

O estudo da legislação educacional brasileira nos mostra que historicamente a pedagogia não objetivava formar professores para lecionar nos Anos Iniciais, assim como ainda acontece com a licenciatura em Matemática. Somente a partir da LDB n . 5.692/71 a formação do professor dos Anos Iniciais foi vinculada ao curso de Pedagogia, porém ainda não se constituía uma exigência legal, mas uma licença para os egressos, pois a formação destes docentes estava diretamente associada aos cursos de nível médio, o magistério.

Mais recentemente, a resolução CNE/CP N 1/2006, com base na LDB nº. 9.394/96, entre outras atribuições, atesta a responsabilidade pela formação dos docentes que atuarão nos Anos Iniciais para os cursos de Pedagogia, como explicitado nos dois artigos a seguir:

Art. $4^{\circ} \mathrm{O}$ curso de Licenciatura em Pedagogia destina-se à formação de professores para exercer funções de magistério na Educação Infantil e nos Anos Iniciais do Ensino Fundamental [...] e em outras áreas nas quais sejam previstos conhecimentos pedagógicos.

Art. $5^{\circ} \mathrm{O}$ egresso do curso de Pedagogia deverá estar apto a:

VI - ensinar Língua Portuguesa, Matemática, Ciências, História, Geografia, Artes, Educação Física, de forma interdisciplinar e adequada às diferentes fases do desenvolvimento humano [...] (BRASIL, 2006).

De acordo com este documento, tal curso tornou-se uma licenciatura, dirigindo-se à formação de docentes para atuarem na Educação Infantil e Anos Iniciais do Ensino Fundamental. Já as ementas de Matemática nos cursos de Pedagogia, em sua maioria, apresentam os elementos metodológicos às vezes com alguma menção à epistemologia da disciplina, mas raramente em articulação com os conteúdos específicos. Em geral, essa não é uma realidade isolada do curso de Pedagogia de uma ou outra instituição, pois segundo Curi (2004), o número de disciplinas que trabalha matemática e seus fundamentos durante o curso de licenciatura em Pedagogia é muito restrito, tendo em vista que esse número varia de uma a quatro disciplinas, conforme a instituição. Para esta pesquisadora, esse é um quadro bastante inquietante, tanto pelo número de horas destinado à formação Matemática de docentes polivalentes, como também em relação à falta de publicações características destinadas a essa formação. 
Nesse sentido, Almeida e Lima (2012) alertam que a formação matemática nos cursos de Pedagogia relega essa disciplina a segundo plano, sendo insuficiente para atender as demandas de uma formação inicial a profissionais que atuarão nos Anos Iniciais. Na mesma direção, Libâneo (2006) atesta que em boa parte dos atuais cursos há relevante ausência de conteúdos específicos no currículo, ficando quase que exclusivamente as metodologias.

Com Gatti (2010), entendemos e legitimamos as falas comuns na academia de que a formação de professores para a Educação Básica é feita de forma fragmentada entre as áreas disciplinares e os níveis de ensino, lembrando também da separação formativa que há entre o professor polivalente e o professor dos Anos Finais do Ensino Fundamental - o chamado professor especialista. Gatti (2010) expõe que essa separação não se dá apenas no âmbito da formação, mas também num âmbito social, como na carreira e salários.

Segundo a autora, entre 2001 e 2006, a oferta de cursos de Pedagogia destinados à formação de professores dos Anos Iniciais do Ensino Fundamental praticamente dobrou (94\%). Gatti (2010) tomou por base o questionário socioeconômico do Exame Nacional de Cursos (ENADE, 2005) e verificou que cerca de 65\% dos alunos escolhem a Pedagogia pelo fato de desejarem ser professores, ao passo que aproximadamente $21 \%$ veem a docência com uma espécie de 'seguro-desemprego' (GATTI, 2010, p. 1361), ou seja, como uma alternativa no caso de não haver uma possibilidade de exercício em outra atividade.

Ao analisar as ementas de cursos de Pedagogia, Bernadete Gatti constatou como um problema para a formação do professor polivalente o fato de os conteúdos específicos das disciplinas ministradas não serem objeto dos cursos de formação inicial. Os cursos preocupam-se em justificar porquê ensinar, mas de forma muito incipiente registram o que e como ensinar (GATTI, 2010, p. 1369). Além das complexidades apontadas pela pesquisadora, ela revela que os cursos de Pedagogia têm grande preocupação em ofertar teorias políticas, sociológicas e psicológicas para contextualizar o trabalho docente. Isso de fato é importante para tornar o professor consciente do trabalho do docente, entretanto, afirma que isto é insuficiente para suas atividades de ensino, concluindo que a relação teoria-prática como proposta em documentos legais e nas discussões se mostra comprometida desde a base formativa.

Entendemos que a abordagem ao ensino de matemática nos cursos de Pedagogia, com base nas leituras realizadas, se mostrou preferencialmente pelo viés metodológico, limitando os egressos de conhecerem outras perspectivas do próprio modo de ser do conhecimento matemático, tanto no que se refere à epistemologia e historicidade, quanto ao seu modo de se constituir como disciplina escolar em termos de conteúdo. 
A análise poderia nos levar a considerar que o explicitado como limitações e fragilidades em relação à matemática nos cursos de Pedagogia mostra-se como (im)possibilidades formativas no que tange ao ensino e à aprendizagem da matemática aos alunos egressos, o que acabaria por comprovar o que muitas pesquisas já atestaram: 'a falta da matemática' nos cursos de Pedagogia. No entanto, optamos em nos voltar à seção anterior desse texto, e ao indício do revelado pela historicidade dos cursos de Pedagogia, qual seja, a docência como solo de onde brota e no qual o próprio modo de ser da Pedagogia tem se constituído. Entendemos que é por essas aberturas que a matemática vem se presentificando nos cursos de Pedagogia, ou seja, solicitando por modificações no próprio modo de ser desse curso de Graduação, chamando a questionar seu sentido orientador e, mais, requerendo que a matemática se faça presente como produção humana, sem prescindir de seus aspectos teóricos e técnicos. Além disso, que aos egressos seja possível desenvolver modos de compreender e tomar para si aspectos do conhecimento matemático técnico-científico numa perspectiva articuladora de compreensões, formativa.

\section{Considerações finais: quais serão as outras páginas do texto formação acadêmica de professores dos Anos Iniciais?}

Para Gadamer (1997), a alma da hermenêutica é a prioridade da relação com o outro, e a vida humana é configurada como processo dialógico, porque para ele, uma palavra que não alcança o outro é morta. Somente compreendemos quem é o outro ao compreendermos a narrativa que ele mesmo ou outros nos fazem.

Com este autor, a formação docente pode ser considerada pelo ponto de vista de uma experiência hermenêutica, da interpretação-compreensão que se abre ao dar-se conta do que se faz, bem como do feito, no qual se constroem sentidos ao atribuir significados ao real vivido para perceber situações e exigências, que necessitam de embasamento teórico de conhecimentos e saberes pela humanidade ao longo dos tempos, já que para esse autor é possível compreender o passado e endereçar ao futuro, por sermos seres históricos.

Isso permite pensar a formação docente como um texto, e é dentro desse repertório de sentidos sociais que a formação possibilita construirmos uma via compreensiva do complexo campo da formação docente.

Assim, consideramos que construímos um texto repertoriado pelos registros históricos e teóricos, bem como pelos sentidos que foram se fazendo a nós nessa via compreensiva do complexo campo da formação inicial docente. O que este texto nos mostrou? 
Além de um entendimento filosófico do termo 'formação', trouxemos aspectos teóricos e históricos acerca do formar institucionalizado na forma de um curso acadêmico: a Pedagogia. E nesse percurso, compreendemos que a identidade múltipla desse curso está em formação, em condição de vir a ser, pois segue na marcha em busca do seu modo ser, desocultando a carência desse curso em atender às demandas da formação em nível superior para a docência dos Anos Iniciais.

Nessa marcha, a matemática se mostrou a nós pelos modos como vem se presentificando nos cursos de Pedagogia, ou seja, solicitando por modificações no próprio modo de ser desse curso de Graduação, chamando a questionar o seu sentido orientador e mais, requerendo que se presentifique como um modo de produção humano em que os egressos teriam a possibilidade de desenvolver modos de compreender e tomar para si aspectos do conhecimento matemático técnico-científico numa perspectiva articuladora de compreensões, formativa.

Chegamos ao final desse texto entendendo que a intenção de dizer o que a Pedagogia é permanecerá sempre em constituição, haja vista que a identidade múltipla do curso como formador do professor dos Anos Iniciais, e mais ainda, do professor de matemática, está a caminho, se fazendo, deixando em aberto possibilidades de a formação do professor se dar. Com isso, deixamos em aberto possibilidades de novos entendimentos acerca da formação do professor que ensina matemática nos Anos Iniciais e, para que o tema permaneça se constituindo, nos questionamos: quais serão as próximas páginas do texto 'a formação acadêmica de professores dos Anos Iniciais'?

\section{REFERÊNCIAS}

ALMEIDA, Marlisa Bernardi de; LIMA, Maria das Graças de. Formação inicial de professores e o curso de Pedagogia: reflexões sobre a formação matemática. Ciênc. educ., Bauru, v. 18, n. 2, p. 451-468, 2012.

ANDRÉ, Marli. Pesquisas sobre formação de professores: tensões e perspectivas do campo. In: FONTOURA, Helena Amaral.; SILVA, Marco (Orgs.). Formação de professores, culturas: desafios à Pós-graduação em Educação em suas múltiplas dimensões. E-book online.

Disponível em: http://www.fe.ufrj.br/anpedinha2011/sobre.html. Acesso em: 5 nov. 2014.

BRASIL. Decreto-Lei no 1.190, de 4 de abril de 1939. Dá organização à Faculdade Nacional de Filosofia. Coleção de Leis da República Federativa do Brasil, Brasília, v. 4, p. 50, 1939. Disponível em: http://www2.camara.leg.br/legin/fed/declei/1930-1939/decreto-lei-1190-4abril-1939-349241-publicacaooriginal-1-pe.html. Acesso em: 22 out. 2013. 
BRASIL. Parecer n. 5/2005. Diretrizes Curriculares Nacionais para o curso de Pedagogia. Relatoras: Clélia Brandão Alvarenga Craveiro e Petronilha Beatriz Gonçalves e Silva. Diário Oficial [da] República Federativa do Brasil, Brasília, DF. Disponível em: portal.mec.gov.br/cne/arquivos/pdf/pcp05_05.pdf. Acesso em: 13 out. 2013.

\section{BRASIL. MEC/CNE. Resolução CNE/CP 1/2006. Institui Diretrizes Curriculares Nacionais para o Curso de Graduação em Pedagogia, licenciatura.}

BRASIL. Senado Federal. Lei no 9.394, de 20 dezembro de 1996. Estabelece as diretrizes e bases da educação nacional. Diário Oficial [da] República Federativa do Brasil, Brasília, DF, p. 27833, 1996. Disponível em: http://www.planalto.gov.brccivil_03/LEIS/L9394.htm. Acesso em: 16 nov. 2013.

BRITO, Rosa Mendonça de. Breve histórico do Curso de Pedagogia no Brasil. Dialógica. v. 1, n. 1, 2006. Disponível em:

http://dialogica.ufam.edu.br/PDF/no1/1breve_historico_curso_pedagogia.pdf. Acesso em: 10 nov. 2016.

CURI, Edda. Formação de professores polivalentes: uma análise de conhecimentos para ensinar matemática e de crenças e atitudes que interferem na constituição desses conhecimentos. 2004. Tese (Doutorado em Educação Matemática) - Pontifícia Universidade Católica, São Paulo, 2004.

CURI, Edda. A formação matemática de professores dos anos iniciais do ensino fundamental face às novas demandas brasileiras. Revista Iberoamericana de Educación, v. 37, n. 5, p. 19, 2005.

FIORENTINI, Dario et al. (org). Mapeamento da pesquisa acadêmica brasileira sobre o professor que ensina matemática: período 2001 - 2012. Campinas-SP: Faculdade de Educação, 2016. Disponível em: http://www.sbembrasil.org.br/sbembrasil/index.php/93biblioteca/115-biblioteca-em-educacao-matematica. Acesso em: 12 mar. 2017.

GADAMER, Hans-Georg. Verdade e Método: traços fundamentais de uma hermenêutica filosófica. Tradução Flávio Paulo Meurer. 1. ed. Petrópolis: Vozes, 1997.

GATTI, Bernadete Angelina. A formação inicial de professores para a Educação Básica: as licenciaturas. Revista USP, São Paulo, n. 100, p. 33-46, dez/jan/fev. 2013-2014.

GATTI, Bernadete Angelina. Formação de professores no Brasil: características e problemas. Educ. Soc., Campinas, v. 31, n. 113, p. 1355-1379, out/dez. 2010. Disponível em: http://www.scielo.br/scielo.php?pid=S010173302010000400016\&script=sci_abstract\&tlng=pt. Acesso em: 15 jan. 2016.

LIBÂNEO, José Carlos. Diretrizes Curriculares da Pedagogia: imprecisões teóricas e concepções estreitas da formação profissional de educadores. Educação \& Sociedade, Campinas, v. 27, n. 96, especial out. 2006.

LIDIO, Henrique. Uma metacompreensão acerca da formação inicial do professor que ensina matemática. Dissertação (Mestrado em Educação Matemática) - Universidade Federal do Paraná, Curitiba, 2015. 
ORLOVSKI, Nelem. A forma-ação do professor que ensina matemática nos anos iniciais. Dissertação (Mestrado em Educação Matemática) - UFPR, Curitiba, 2014.

ORLOVSKI, Nelem; MOCROSKY, Luciane Ferreira. Professor que ensina matemática nos anos iniciais: re-tratando seu acontecer histórico. Jornal Internacional de Estudos em Educação Matemática, v. 9, p. 86-114, 2016.

TANURI, Maria Leonor. História da formação de professores. Revista Brasileira de Educação, Campinas-SP, v. 14, p. 61-88, maio/ago., 2000.

\section{Como referenciar este artigo}

MOCROSKY, L. F. et al. O professor que ensina matemática nos Anos Iniciais: uma abertura ao contínuo acontecer histórico. Revista Ibero-Americana de Estudos em Educação, Araraquara, v. 14, n. 1, p. 222-236, jan./mar., 2019. E-ISSN: 1982-5587. DOI: 10.21723/riaee.v14i1.10894

Submissão: 16/01/2018

Revisões requeridas: 24/04/2018

Aprovação final: 20/08/2018 